ARTIGO Revista de Ciências Agrärias

AUTORES:

Lindaura Arouck Falesi ${ }^{1}$

Antônio Cordeiro de Santana ${ }^{2}$

Alfredo Kingo Oyama

Homma $^{3}$

Sergio Castro Gomes ${ }^{4}$

${ }^{1}$ Universidade Federal do Pará, 66075-110, Belém, PA, Brasil.

${ }^{2}$ Instituto Sóciombiental e Recursos Hídricos, Universidade Federal Rural da Amazônia, 66.077-530, Belém, PA, Brasil.

${ }^{3}$ Embrapa Amazônia Oriental, 66095-100, Belém, PA. Brasil.

${ }^{4}$ Universidade da Amazônia UNAMA, 66060-902, Belém, PA. Brasil.

Recebido: 20/10/2009 Aprovado: 20/05/2010

AUTOR CORRESPONDENTE:

Lindaura Arouck Falesi

Email:lindaura@ufpa.br

PALAVRAS-CHAVE:

Frutas da amazônia,

Índice de preços,

Taxa de crescimento,

Oferta inelástica.

KEY WORDS:

Amazon fruits,

Price indexes,

Growth rate.

Inelastic supply.

\section{Evolução e interação entre a produção e o preço das frutas no Estado do Pará}

\author{
Evolution and interaction between fruit \\ production and price in the State of Pará
}

Resumo: As frutas apresentaram consistente superávit, em 2005, de R\$ 32,52 milhões, no comércio interestadual do Pará. A produção se estabilizou no patamar de 1,4 milhões de toneladas e os preços em R\$ 160,00 por tonelada, entre 2000 e 2005 . O objetivo do trabalho foi analisar o comportamento das quantidades e dos preços das frutas paraenses, no período de 1985 a 2005. Utilizaram-se o método da taxa de crescimento, a construção de índices de preços e de quantidades e análise de regressão para determinar o crescimento, a evolução e a interação causal entre quantidade e preço. Os resultados mostraram que a produção de frutas cresceu até 1995, depois apresentou tendência de queda até 2000 e, a partir deste ponto, se estabilizou. Os preços apresentaram tendência de queda no período. As frutas extrativas apresentaram baixo coeficiente de elasticidade-preço $(0,114)$, caracterizando a oferta como fortemente inelástica a preço. Conclui-se que a receita bruta das frutas extrativas é fortemente sensível às variações da produção.

Abstract: There was a consistent surplus in the State of Pará's fruit sector in 2005 of $\mathrm{R} \$ 32.52$ in terms of interstate trade. Production stabilized at 1.4 million tonnes and the price at $\mathrm{R} \$ 160$ per tonne between the years 2000 and 2005 . The aim of this study was to analyze the quantity of fruit produced and price fluctuation for Pará's fruits between 1985 and 2005. The growth rate method, price indexes and quantities, and regression analysis were used to ascertain the increase, evolution and causal interaction between quantity and price. Results showed that fruit production increased until the year 2005, then presented a downward trend until the year 2000, and subsequently stabilized. Prices presented a downward trend over this period of time. The fruits showed a low priceelasticity coefficient (0.114), which is characteristic of a highly priceinelastic supply. It was concluded that the gross revenue for these fruits is highly sensitive to variations in production. 


\section{Introdução}

A economia agrícola paraense, segundo Santana (2009), pode ser enquadrada como "primária exportadora", em função de suas âncoras de sustentação se assentarem na produção agrícola, pecuária, pesca e madeira, e na extração e beneficiamento inicial dos minerais metálicos e não metálicos. A produção agrícola ainda é de base familiar, com os produtos de alimentação (arroz, feijão, milho, hortaliças e mandioca) e os produtos de renda, como a pimenta do reino, cacau e fruticultura de quintais, dado que a produção em escala apenas se inicia com tecnologia de altos insumos.

De acordo com Santana, Carvalho e Mendes (2008) e Homma e Santana (2009), a fruticultura de quintais envolve a produção de banana, manga, caju, coco e citros, principalmente, que se constitui de alguns pés plantados no entorno das residências das comunidades rurais. Do extrativismo, tem-se o bacuri, castanha-do-pará, taperebá, cupuaçu, pupunha e açaí. O açaí está sendo manejado na várzea e se expandindo na forma de plantios em consórcio e/ou em sistemas agroflorestais com o cupuaçu e diversas essências florestais e, mais recentemente, passou a ser cultivado em terra firme e com irrigação em plantios homogêneos.

Há também grandes plantios em monocultivo de abacaxi, laranja e coco. O maracujá, acerola, camucamu, abacate, goiaba, entre outras, são cultivadas por pequenos agricultores na mesorregião Nordeste paraense, onde a concentração é dominante (SANTANA; AMIN, 2002; SANTANA, 2009). Toda a produção de frutas, exceto abacaxi, laranja e maracujá, é comercializada internamente no Estado do Pará.

Em termos do comércio interestadual, a fruticultura gerou superávit, em 2008, de R\$ 56,48 milhões, com incremento de $22,16 \%$ em relação a 2005 (SANTANA, 2009). Apesar da entrada de frutas como uva, maçã e goiaba, o Pará vendeu laranja, abacaxi, maracujá, castanha-do-pará e coco verde, principalmente. Em 2008, as vendas de frutas para as demais unidades federativas somaram mais de meio bilhão de reais ( $\mathrm{R} \$ 594,96$ milhões), representando $75,09 \%$ do valor total das vendas de produtos da agricultura.

Para o mercado internacional, em 2008, o Pará exportou, em frutas, sucos e polpa, o valor de $\mathrm{R} \$ 29.998$ mil. Deste total, a polpa de açaí representou 68,29\%, conforme Santana (2009) e Homma e Santana (2009). Diante da crise econômica inter- nacional, a fruticultura não sofreu interrupção da tendência de crescimento, enquanto as exportações de grãos e pimenta-do-reino foram influenciadas, mesmo antes da crise, em função do câmbio valorizado. Como o Pará não importou frutas do resto do mundo, o superávit foi igual às exportações, isso o torna exportador líquido nos produtos da cadeia produtiva de fruticultura.

O contexto apresentado mostra que o Estado do Pará deixou de ser um importador líquido de frutas do mercado brasileiro e marcou sua inserção no mercado internacional. Esta conquista de mercado da fruticultura merece uma investigação para entendimento sobre os fatores que determinaram sua evolução nas últimas décadas. Como se deu a expansão da fruticultura paraense? Foram os estímulos de preços ou apenas a vocação da produção para a subsistência no âmbito da agricultura familiar? A resposta para essas perguntas foi o objeto de investigação deste trabalho.

O objetivo do trabalho foi aplicar a metodologia das taxas de crescimento e construção de índices de quantidade, preço e valor bruto da produção das frutas cultivadas e extrativas e das demais lavouras ao longo do período de 1985 a 2005.

\section{Material e Métodos}

A área de estudo foi o Estado do Pará, por sua diversificação de frutas regionais de importância para o consumo local e de valor e interesse comercial como o açaí, o cupuaçu e outras frutas produzidas em larga escala, como abacaxi, coco e laranja. Tudo em função das condições de clima e solo favoráveis. Apesar dessa importância revelada, os estudos sobre a evolução da fruticultura paraense são escassos e se prendem, na maioria das vezes, a uma simples análise de conjuntura.

A base de dados foi coletada de diversas fontes secundárias. As informações de quantidade e valor bruto da produção foram obtidas do IBGE (2009), do Anuário da Agricultura Brasileira - Agrianual (2005) e do Anuário Brasileiro da Fruticultura (2008).

As frutas utilizadas na pesquisa seguiram a estrutura de classificação do IBGE, assim consideradas: frutas de culturas temporárias: abacaxi (Ananás comosus), melancia (Citrullus vulgaris) e melão (Cucumis melo); frutas de culturas permanentes: abacate (Pérsia americana), acerola (Malpighia glabra), banana (Musa spp.), cacau (Theobroma cacao), cupuaçu (Theobroma grandiflorum), coco- 
da-baía (Cocos nucifera), caju (Anacardium ocidentatale), goiaba, (Psidium guayava) guaraná (Paullinia cupana va.), laranja (Citrus sinensis), limão (Citrus limonia), mamão (Carica papaya), manga (Mangifera indica), maracujá (Passiflora edulis) e tangerina (Citrus nobilis var. deliciosa); frutos do extrativismo vegetal: açaí (Euterpe oleracea) e castanha-do-pará (Bertholettia excelsa).

O modelo estatístico utilizado foi da análise de tendência (SANTANA, 2003b) e do índice de quantidade e dos preços das frutas tropicais (TOLEDO; OVALE, 1995).

\subsection{Modelo de Tendência e Índice de Quantidade e Preço}

O modelo de tendência na forma foi utilizado para determinar a taxa geométrica de crescimento da produção, dos preços, do salário rural e da PIB per capita, para o Estado do Pará e para a mesorregião Nordeste paraense.

Para avaliar a taxa de crescimento ao longo do período, trabalhou-se com o modelo da taxa geométrica de crescimento, especificada do seguinte modo (SANTANA, 2003b):

$$
Y_{t}=Y_{0}(1+r)^{t}
$$

em que $Y_{t}$ é a variável econômica (quantidade, preço, salário rural e PIB) no período $t$; $Y_{0}$ é o valor da variável no período base (inicial) e $r$ é a taxa de crescimento. A equação acima pode ser linearizada por anamorfose, tomando o logaritmo natural de ambos os lados da equação, como a seguir:

$$
\ln Y_{t}=\ln Y_{0}+t \ln (1+r)
$$

fazendo $a=\ln Y_{0}$ e $b=\ln (1+r)$ e adicionando o termo de erro aleatório, pode-se reescrever a equação da seguinte forma:

Modelo log-linear: $\ln Y_{i}=a+b t i+e_{i}$ em que:

$\ln Y_{i}$ é o logaritmo natural da variável econômica (quantidade, preço, salário rural e PIB), no período i;

a é a constante ou intercepto da regressão;

$b$ é o coeficiente de tendência da regressão;

$t_{i} \quad$ é o valor da variável de tempo no período i;

$e_{i} \quad$ é o termo de erro aleatório, sob as hipóteses estatísticas clássicas.
A constante não tem significado econômico. Por outro lado, o coeficiente de tendência indica o incremento relativo no valor da variável econômica $Y$ em relação a um aumento de uma unidade na variável de tempo.

Conforme Santana (2003b):

\begin{abstract}
Os modelos de tendência têm como finalidade avaliar o comportamento de variáveis econômicas ao longo do tempo, considerando a estacionariedade do tempo. Por tendência entende-se o movimento persistente e contínuo, crescente ou decrescente, da variável econômica Y. Se o coeficiente de tendência for positivo, há uma tendência crescente em Y; se for negativo, a tendência é decrescente.
\end{abstract}

Para análise do comportamento temporal das variáveis, utilizou-se o índice ponderado para quantidades e preços das frutas e outras culturas do Estado do Pará e da mesorregião Nordeste Paraense, no período de 1985 a 2005.

Segundo Toledo e Ovale (1995), os índices agregados de quantidade e de preços de Laspeyres são especificados da seguinte forma:

Índice de quantidade: $\mathbf{I} \mathbf{Q}=\frac{\sum_{\mathrm{i}=1}^{\mathrm{n}} Q_{\mathrm{t}}^{\mathrm{i}} \mathrm{P}_{\mathrm{o}}^{\mathrm{i}}}{\sum_{\mathrm{i}=1}^{\mathrm{n}} \mathrm{Q}_{\mathrm{o}}^{\mathrm{i}} \mathrm{P}_{\mathrm{o}}^{\mathrm{i}}}$

Em que: Qé a quantidade da fruta i (tonelada) no ano t e no ano base (zero); P é o preço da fruta i, no ano base.

Este índice permite verificar o valor da produção, com base nas quantidades do ano te relação ao mesmo valor do ano base. Se as quantidades variarem em relação ao ano base, o índice revela o comportamento dessa variação ao longo do tempo.

$$
\text { Índice de preços: } \mathbf{I P}=\frac{\sum_{\mathrm{i}=1}^{\mathrm{n}} \mathrm{Q}_{\mathrm{t}}^{\mathrm{i}} \mathrm{P}_{\mathrm{t}}^{\mathrm{i}}}{\sum_{\mathrm{i}=1}^{\mathrm{n}} \mathrm{Q}_{\mathrm{o}}^{\mathrm{i}} \mathrm{P}_{\mathrm{o}}^{\mathrm{i}}}
$$

Este índice permite verificar o valor da produção com base nos preços do ano t em relação ao mesmo valor aos preços do ano base. Se os preços variarem em relação ao período base, o índice revela o comportamento dessa variação de preço ao longo do tempo.

\subsubsection{Relações entre quantidades e preços de frutas}

A relação entre as quantidades produzidas de frutas e os preços de mercado destas frutas foi avaliada por meio de um modelo de regressão simples, especificado de acordo com Santana (2003).

$$
\ln Q F_{\text {it }}=\alpha+\beta \ln P F_{\text {it }}+\varepsilon_{\text {it }}
$$

Em que: LnQF é a quantidade da fruta i no período t; $\ln \mathrm{PF}$ é o preço da fruta i no período t; a e b são 
os parâmetros a serem estimados e $\varepsilon$ é o termo de erro aleatório.

Com a estimação deste modelo espera-se mostrar a relação causal entre preços e quantidades ofertadas das frutas totais e das frutas extrativas do Estado do Pará, no período de 1985 a 2005.

\section{Resultados e Discussão}

\subsection{Taxas de Crescimento da Produção e Preços das Frutas}

As informações da produção de frutas do Pará foram agregadas de duas formas: a primeira contempla toda a produção de frutas cultivadas e extrativas e na segunda agregaram-se apenas as frutas oriundas do extrativismo. Essa agregação foi feita para o Estado do Pará e para a mesorregião Nordeste Paraense, que concentra as atividades cultivadas racionalmente.

Com base nas informações do Figura 1, tem-se que a produção total de frutas do Pará como um todo e a da mesorregião em particular não cresceram estatisticamente no período de 1995 a 2005 , dado que tais estatísticas não foram diferentes de zero. Isto significa que, embora os valores da taxa geométrica de crescimento apontem para um crescimento da produção de frutas do Pará como um todo e decréscimo da produção da mesorregião Nordeste paraense, ao longo do período tal produção se acomodou em patamar não diferente do período inicial.

Com relação às frutas oriundas exclusivamente do extrativismo, houve um decréscimo de -1,01\% ao ano e $-1,93 \%$ ao ano, respectivamente, para o Estado do Pará e para a mesorregião Nordeste paraense, pois as estatísticas foram diferentes de zero a $5 \%$ de probabilidade. Este resultado pode indicar, para o Pará, que a produção extrativa está caindo em função da depredação (caso da castanhado-pará) e por dar lugar à produção cultivada, inclusive destas frutas, por meio da domesticação e plantios racionais, como está ocorrendo com o cupuaçu e o açaí. A evolução do plantio racional em monocultivo, em consórcios ou em agrossistemas planejados, tem como foco o abastecimento das agroindústrias produtoras de polpas e sucos de frutas (SANTANA; CARVALHO; MENDES, 2008; HOMMA; SANTANA, 2009).

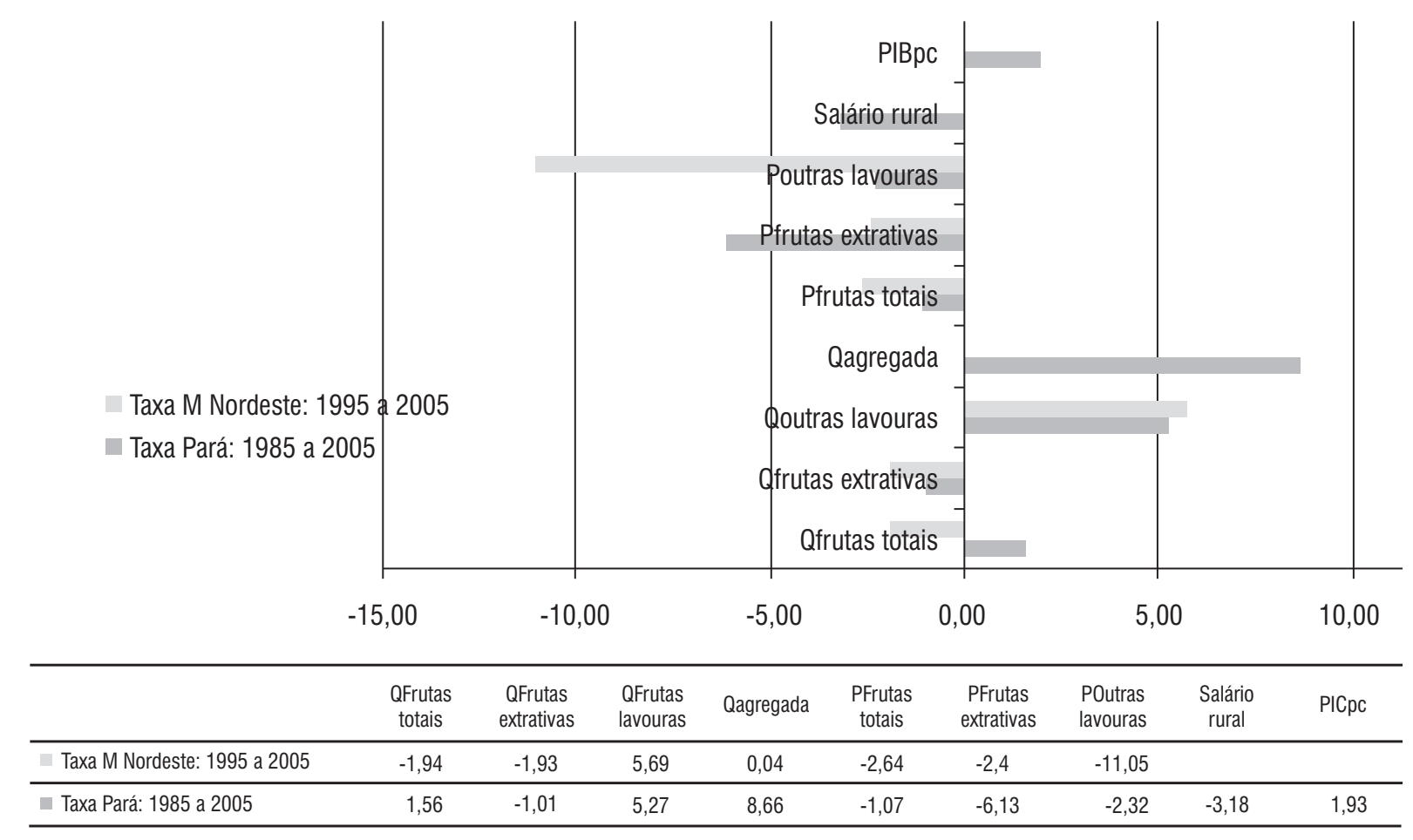

Figura 1- Taxas de crescimento das frutas tropicais na mesorregião Nordeste paraense no período de 1995-2005 e no Estado do Pará no período de 1995-2005, comparativamente ao PIBpc, salário rural, outras lavouras.

Fonte: Censos Agropecuários do Pará: 1985-2005.

Conjuntura Econômica, Rio de Janeiro, FGV, v. 61, n. 3, mar. 2007.

LSPA: Levantamentos Sistemáticos da Produção Agrícola no Estado do Pará: 1999/2003.

Identificação das variáveis: PIBpc: Produto Interno Bruto per capita; P frutas totais; preços de frutas totais; Qagregada: Quantidade Agregada de frutas; QFrutas Extrativas: Quantidades de frutas extrativas; QFrutas totais: Quantidades de frutas totais. 
Com relação ao conjunto de outras lavouras, observou-se um incremento anual estatisticamente significativo de 5,27\% ao ano e 5,69\% ao ano, respectivamente, no Pará e na mesorregião Nordeste. Este desempenho pode estar ligado ao avanço da produção de grãos, conforme Filgueiras, Ferreira e Santana (2007).

Com relação à taxa geométrica de crescimento dos preços das frutas totais, houve uma tendência de queda estatisticamente significativa de -2,64\% ao ano na mesorregião Nordeste e comportamento estável para o Estado do Pará, uma vez que a taxa não foi diferente de zero. Os preços das frutas extrativas apresentaram comportamento inverso, dado que houve uma forte tendência de queda nos preços, estatisticamente significativa, de $-6,13 \%$ ao ano, no período estudado. Enquanto que na mesorregião Nordeste os preços variaram em torno de um mesmo patamar em vigor no início do período.

Os preços de outras lavouras, por sua vez, apresentaram forte queda de $-2,32 \%$ ao ano e $-11,05 \%$ ao ano, respectivamente, para o Estado do Pará e para a mesorregião Nordeste. Este resultado pode estar associado com a expansão da produção no período que, em função das características de inelasticidade, o preço da oferta destes produtos causou forte impacto nos preços no período de pico de safra. Em conjunto com este fator de mercado, também deve ter contribuído para isto a precariedade da infraestrutura de comercialização dos produtos (armazenamento, transporte) e da política de garantia de preços na comercialização dos produtos.

O salário rural, principal item dos custos de produção da agricultura paraense, apresentou tendência de queda estatisticamente diferente de zero, de $-3,18 \%$ ao ano, ao longo do período analisado. Isto indica uma queda nos custos de produção de um lado, ou da ampliação do emprego de máquinas e insumos químicos nos tratos culturais das lavouras, fazendo com que se formasse um excedente de mão de obra no meio rural, ao longo deste período. Esta hipótese é confirmada nas lavouras de grãos, que são intensivas no uso de capital. Mesmo na pequena agricultura, aumentou a rotatividade do emprego no campo, em função da legislação trabalhista, que tornou inviável a contratação de trabalho formal no âmbito da produção em pequena escala.

Finalmente, o produto interno bruto (PIB) per capita apresentou uma taxa de crescimento de 1,93\% ao ano, entre 1985 e 2005 , mostrando que houve uma melhora no poder de compra médio da população paraense.

\subsection{Evolução das Quantidades e Preços das Frutas}

Nesta seção, analisaram-se as informações geradas a partir dos índices de quantidade e preço do Estado do Pará e da mesorregião Nordeste Paraense, no período de 1985 a 2005.

\subsubsection{Evolução das Quantidades}

No Figura 2, tem-se o comportamento do índice de quantidades de Laspeyres para frutas como um todo, frutas extrativas e outras lavouras. Observase que a produção de frutas totais cresce sistematicamente até 1995, quando inicia uma tendência de queda, que se prolongou até o ano 2000. A partir deste ponto a produção se estabilizou em patamar acima da produção estabelecida no ano de 1985, considerado como base.

Neste período, a década de 90 (1990 a 1999) apresentou comportamento cujos incrementos da produção alcançaram o patamar médio de $65,9 \%$ em relação ao ano de 1985, chegando, em 1995, a 81,8\%. Esta foi a década da fruticultura no Pará, que avançou com os plantios de abacaxi, coco, goiaba, laranja, maracujá e acerola, principalmente, tanto no âmbito da pequena produção quanto em grandes áreas homogêneas (SANTANA, 2007; HOMMA; SANTANA, 2009). Esta produção, embora tenha ganhado expressão espacial em diversas localidades do Pará, foi na mesorregião Nordeste paraense que houve sua maior concentração, conforme indicam as informações da Figura 3 (SANTANA; AMIN, 2002; SANTANA, CARVALHO, MENDES, 2008). Este comportamento foi fortemente influenciado pelo volume de recursos do Fundo Constitucional de Financiamento do Norte (FNO), que custeou a implantação desta base produtiva (SANTANA, 2003a).

No período subsequente ao "boom", iniciado no século XXI, a produção se acomodou em patamar inferior, com média de $29,5 \%$ acima da produção de 1985. A razão desta queda relativa à década anterior se deveu ao intenso ataque de pragas e doenças, que praticamente inviabilizou os plantios de acerola e maracujá e à diminuição do apoio creditício a essas lavouras (SANTANA, 2002). Mesmo assim, o coeficiente de variação da fruticultura paraense foi de apenas $16,41 \%$, considerado como de instabilidade de média proporção.

O comportamento da produção de frutas extrativas se manteve praticamente no mesmo patamar, mostrando que a produção das frutas regionais ainda tem no extrativismo sua principal oferta (Figuras 2 e 3). 
Falesi et al. / Rev. Ci. Agra., v.53, n.1, p.69-77, Jan/Jun 2010

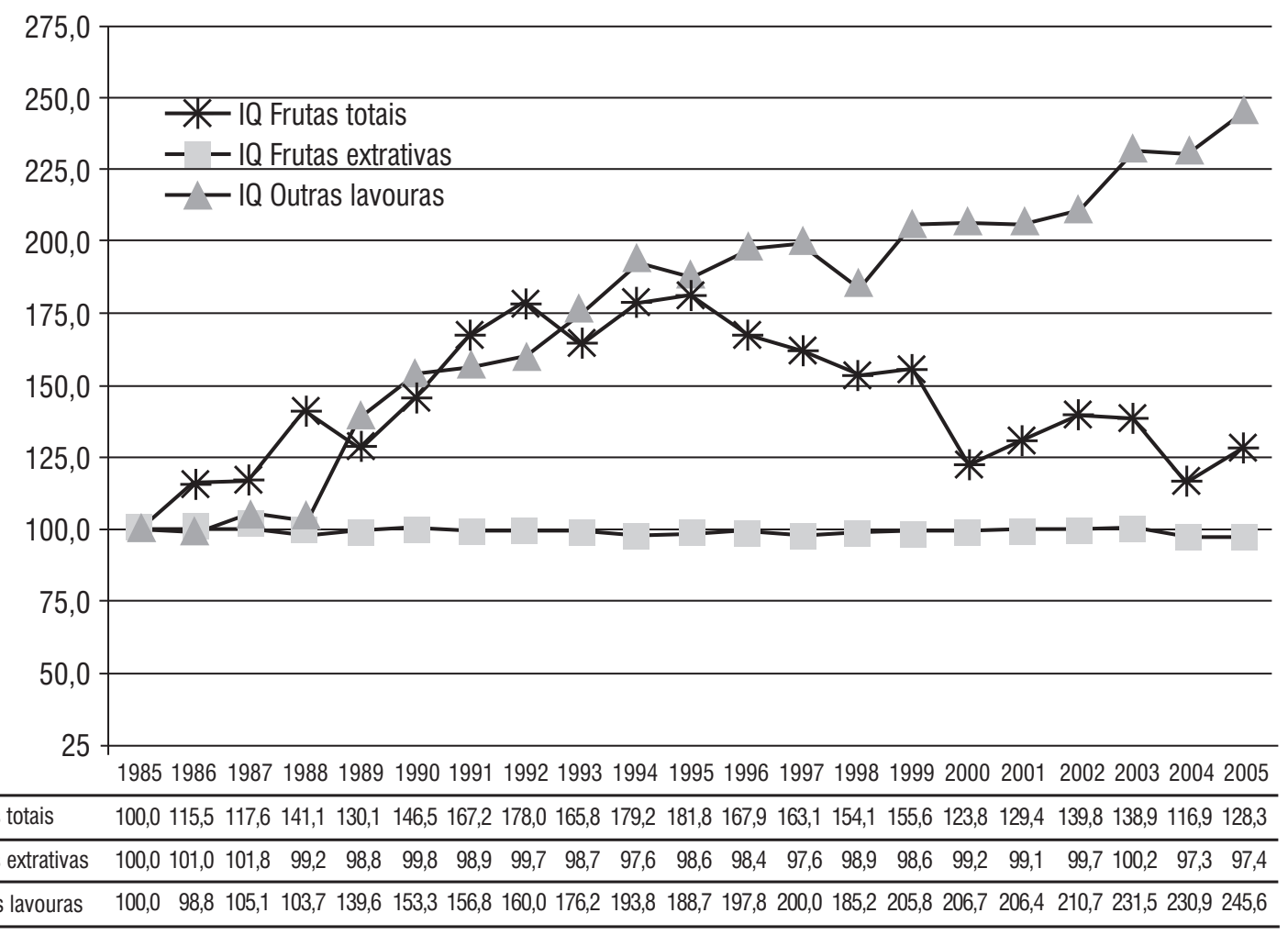

Figura 2 - Índices de Quantidades das frutas tropicais no Estado do Pará, no período de 1985-2005, comparativamente a lavouras de frutas, outras lavouras e lavouras de frutas extrativas.

Fonte: Censos Agropecuários do Pará: 1985-2005.

LSPA: Levantamentos Sistemáticos da Produção Agrícola no Estado do Pará: 1999/2003.

Conjuntura Econômica, Rio de Janeiro: FGV, v.61, n.3, mar.2007.

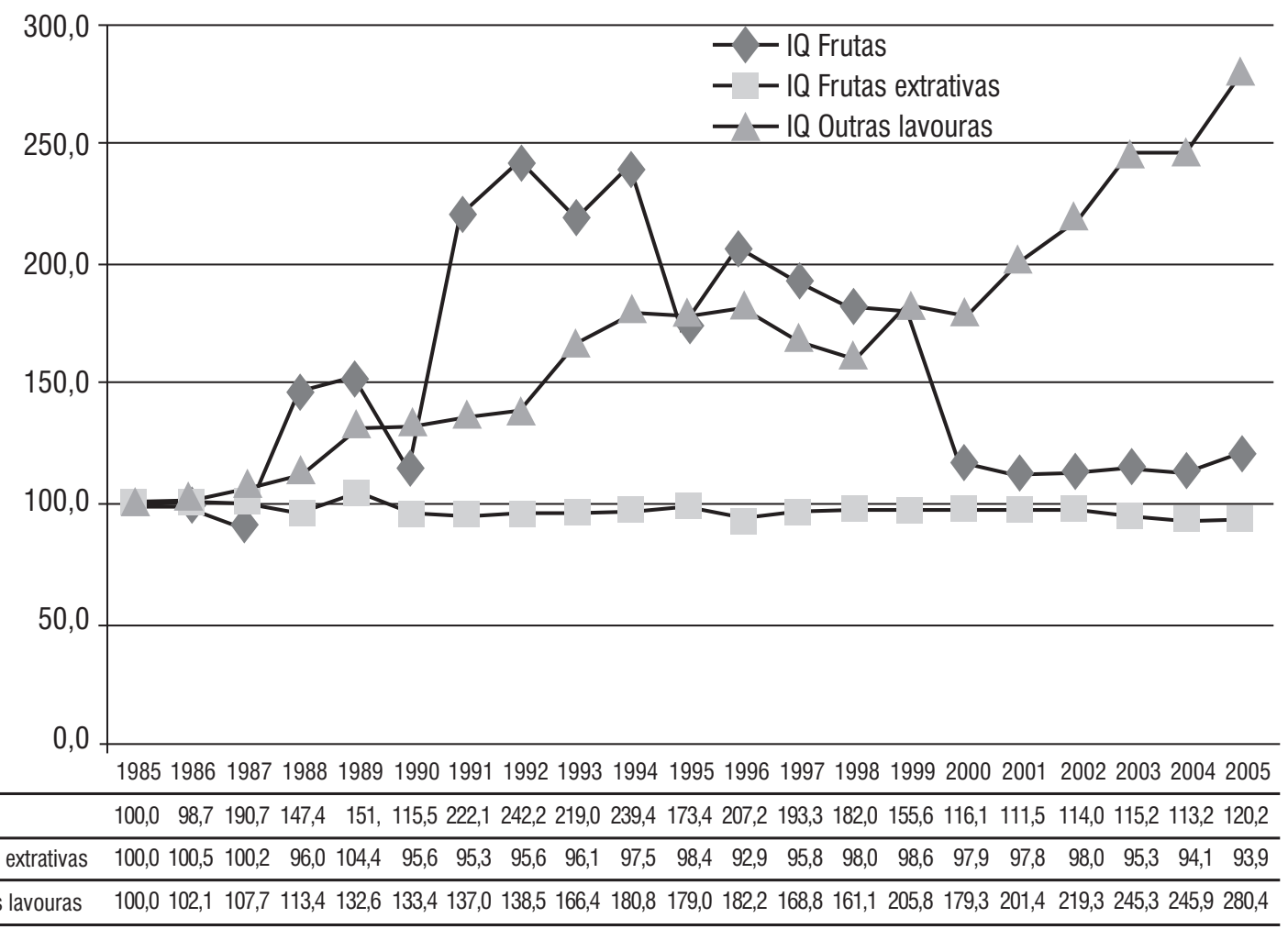

Figura 3 - Índices de Quantidades das frutas tropicais na mesorregião Nordeste paraense, no período de 1985-2005, comparativamente a outras lavouras e lavouras de frutas extrativas. Fonte: Censos Agropecuários do Pará: 1985-2005. LSPA: Levantamentos Sistemáticos da Produção Agrícola no Estado do Pará: 1999/2003.Conjuntura Econômica, Rio de Janeiro: FGV, v.61, n.3, mar.2007. 
Com relação às outras lavouras, é nítida a evolução da produção, chegando ao patamar de 145,6\% de incremento em relação ao ano base, com sinais claros de que a tendência deve se prolongar, pois ganhou novo ritmo a partir de 2002 (Figuras 2 e 3).

\subsubsection{Evolução dos preços}

Os preços das frutas totais e das frutas extrativas exibiram comportamento linear decrescente ao longo do período, tendo o preço das frutas extrativas apresentado uma maior estabilidade, tanto para o Estado do Pará como para a mesorregião Nordeste paraense (Figuras 4 e 5).

Até 1995, os preços das frutas extrativas oscilaram mais fortemente do que os preços de frutas totais. No período de 1995 a 2005, por sua vez, os preços das frutas totais apresentaram oscilações mais fortes, pois o coeficiente de variação foi de
$2,19 \%$ contra $0,72 \%$ para as frutas extrativas.

O diferencial do comportamento ficou com os preços de outras lavouras que, no Estado do Pará, exibiram uma forte tendência de queda até 1990, quando se inicia uma fase de estabilidade que se prolongou até 1995 (Figuras 4 e 5). No início do período, a queda drástica de preços se deu pela expansão muito rápida da produção, sem o acompanhamento em tempo da infraestrutura de comercialização e da funcionalidade dos instrumentos de política agrícola. Depois a produção segue um curso de evolução previsível e os preços se acomodam em patamar em torno dos 55\%, inferior ao ano de 1985 . A partir daí, os preços saltam e se estabilizam em outro patamar, em torno dos $45 \%$, inferior ao preço do ano-base. A razão da queda de preço foi que, neste periodo, a produção praticamente triplicou, substituindo a importação e melhorando o abastecimento interno.

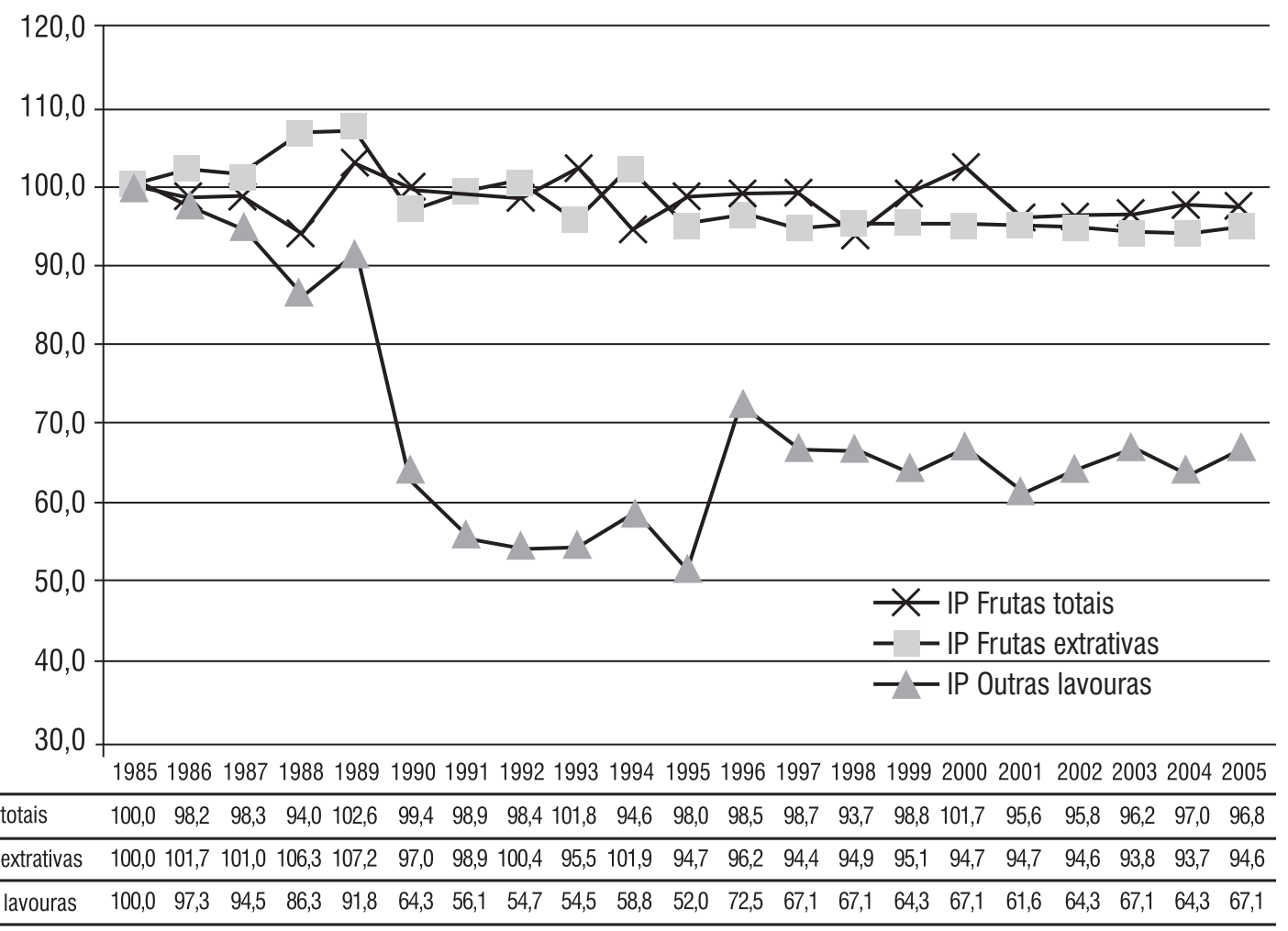

Figura 4 - Índices de preços das frutas tropicais no Estado do Pará, no período de 1985-2005, comparativamente aos preços de frutas totais, frutas extrativas e outras lavouras.

Fonte: Censos Agropecuários do Pará: 1985-2005.

LSPA: Levantamentos Sistemáticos da Produção Agrícola no Estado do Pará: 1999/2003.

Conjuntura Econômica, Rio de Janeiro: FGV, v.61, n.3, mar.2007. 
Falesi et al. / Rev. Ci. Agra., v.53, n.1, p.69-77, Jan/Jun 2010

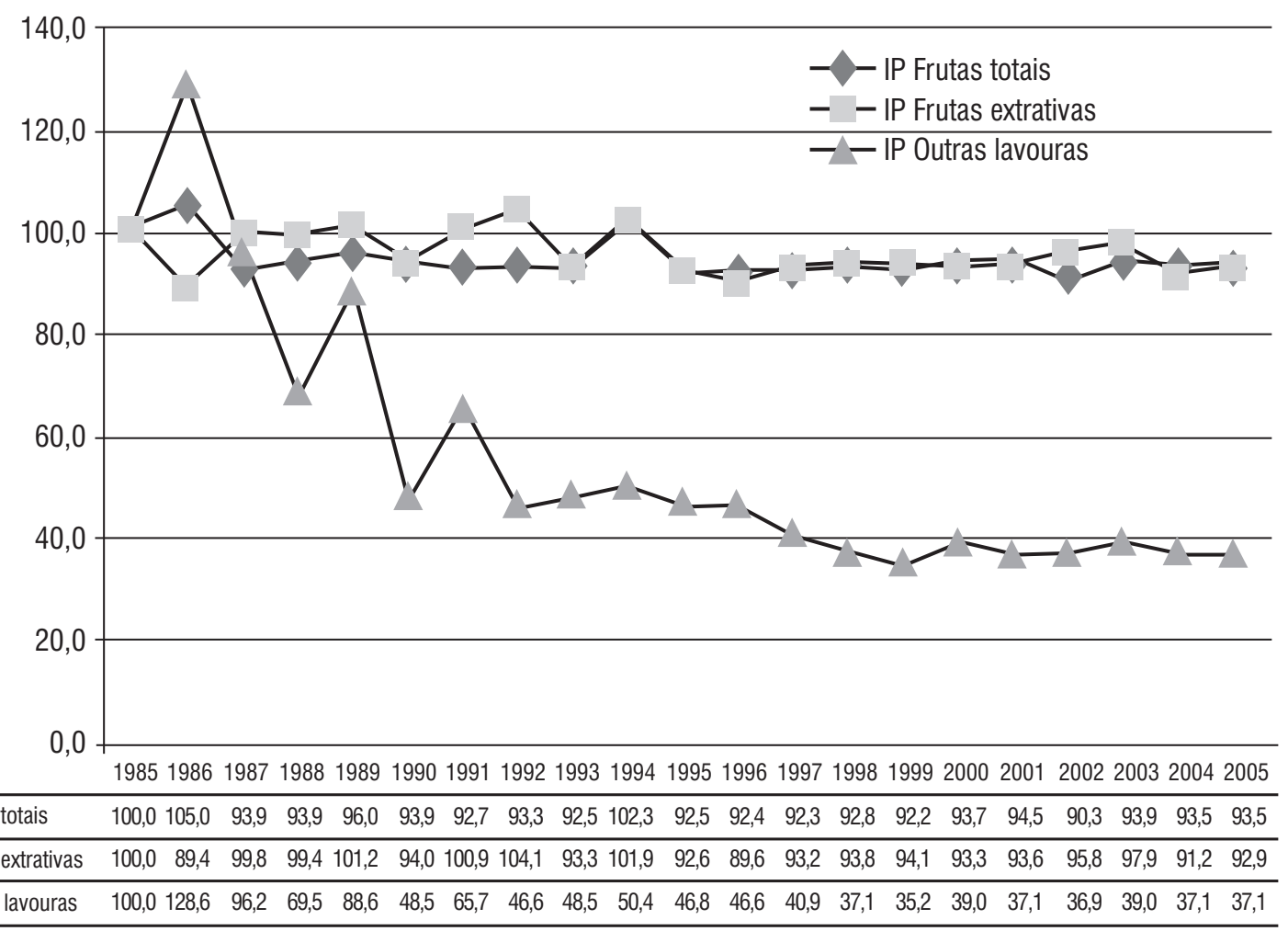

Figura 5 - Índices de preços das frutas tropicais na mesorregião Nordestes paraense, no período de 1985-2005, comparativamente a preços totais de frutas, outras lavouras e lavouras de frutas extrativas

Fonte: Censos Agropecuários do Pará: 1985-2005.

LSPA: Levantamentos Sistemáticos da Produção Agrícola no Estado do Pará: 1999/2003.

Conjuntura Econômica, Rio de Janeiro: FGV, v.61, n.3, mar.2007.

\subsubsection{Relação entre Quantidades e Preços}

Os resultados apresentados para quantidades e preços indicam claramente alguns resultados interessantes do ponto de vista econômico. Em primeiro lugar, tem-se que a oferta de frutas do extrativismo se manteve praticamente em torno da média de 120 mil toneladas, independente da tendência de queda dos preços, mostrando que a oferta de produtos extrativos está próxima à inelasticidade perfeita. Ou seja, a quantidade ofertada se manteve no mesmo patamar, independentemente das variações de preços.

Este resultado foi confirmado com a estimação da equação de oferta marshaliana tradicional, conforme equação: $\ln P F P A=6,28_{(4,07)}-0,08_{(-0,74)} \ln Q F P A$. Estes resultados indicam que os preços se mantiveram constantes diante das variações nas quantidades produzidas no período analisado, mostrando que os produtores de frutas são tomadores de preços.

O segundo resultado importante foi que as frutas totais acompanharam o comportamento normal da oferta em relação ao preço, com a produção variando diretamente com o comportamento dos pre- ços. Isto é nitidamente verificado a partir de 1994 , quando os preços e as quantidades de frutas apresentam tendência de queda.

Os resultados da equação de oferta de frutas extrativas estimada mostraram a existência de elevado grau de inelasticidade-preço $(0,114)$, mostrando que para cada incremento de $10 \%$ nos preços, as quantidades ofertadas de frutas extrativas tendem a aumentar $0,114 \%$, no período analisado. O modelo de oferta apresentou significância estatística a 5\% de probabilidade.

$$
\begin{gathered}
\ln Q F E x P A=11,0_{(33,98)}+0,114_{(2,11)} \ln P F E x P A ; \\
R^{2}=0,198 ; F=4,55 ; d=1.19 .
\end{gathered}
$$

Este resultado significa que a oferta de frutas extrativas torna a receita do produtor extremamente instável diante das variações na produção. Assim, uma maior quantidade ofertada do produto pode causar uma forte redução na receita bruta do produtor por conta do coeficiente de elasticidade ser baixo, ceteris paribus.

Por fim, a produção de outras lavouras exibiu comportamento diverso, com uma correlação 
negativa apresentada no período de 1985 a 1993 e de quase independência, entre preço e quantidade, no período de 1997 a 2005. Neste período, a produção aumentou rapidamente, enquanto os preços permaneceram praticamente no mesmo patamar. Então, deduz-se que os ganhos econômicos estão sendo gerados em função do aumento da produtividade e da expansão da área, juntamente com a redução dos custos de produção. Ou seja, a esse patamar de preços, a agricultura paraense é viável pela soma dos efeitos de rendimento e área cultivada.

\section{Conclusão}

A produção de frutas extrativas apresentou tendência significativa de queda, tanto no Pará como na mesorregião Nordeste paraense. A produção de frutas totais, por sua vez, cresceu até 1995, depois caiu até 2000, quando se estabilizou em patamar superior ao praticado no período inicial.

Os preços das frutas cultivadas e extrativas apresentaram tendência de queda no período de 1985 a 2005.

Com relação às outras lavouras, a produção apresentou forte tendência de crescimento, enquanto os preços caíram no mesmo período.

Os salários rurais diminuíram à taxa de 3,18\% ao ano, enquanto o PIB per capita do Pará cresceu à taxa de 1,93\% ao ano, entre 1985 e 2005.

As frutas extrativas apresentaram comportamento de oferta fortemente inelástica a preço, uma vez que a produção permaneceu praticamente constante diante das variações dos preços.

A produção de frutas evoluiu em função do efeito área com cultivos racionais e do apoio creditício e caiu por causa da influência forte do ataque de pragas e doenças, uma vez que a produção das frutas extrativas permaneceu praticamente constante ao longo do período.

\section{Referências}

ANUÁRIO BRASILEIRO DA FRUTICULTURA. Santa Cruz do Sul: Gazeta Santa Cruz, 2008. <<
ANUÁRIO DA AGRICULTURA BRASILEIRA (Agrianual). São Paulo: FNP, 2005.

FILGUEIRAS, G.C.; FERREIRA, M.N.C; SANTANA, A.C. de. Análise do mercado e da concentração espacial da cadeia produtiva da soja Amazônica. Belém: Basa. Geder, 2007. Disponível em: < http//www.bancoamazonia.com.br/bibliotecavirtual>. Acesso em: 3 mar. 2010.

HOMMA, A.K.O.; SANTANA, A.C. de. A agroindústria na região Norte. In: ZIBETTI, D.W.; BARROSO, L.A. Agroindústria: uma análise no contexto socioeconômico e jurídico. São Paulo: LEUD, 2009.

IBGE. Censo agropecuário 2006. Rio de Janeiro: 2009.

SANTANA, A.C. de. Análise das contas correntes do balanço de pagamentos interestadual do Estado do Pará, período 2005 a 2008. Belém: BNDES, 2009. 50p. (Relatório de Pesquisa).

Análise do desempenho competitivo das agroindústrias de polpa de frutas do Estado do Pará. Teoria e Evidência Econômica, v.14, p.36-62, 2007.

O Fundo Constitucional de Financiamento do Norte e o desenvolvimento da Amazônia. Belém: Banco da Amazônia, 2003a.

Métodos quantitativos em economia: elementos e aplicações. Belém: Graphitte Editores, 2003b.

; AMIN M.M. Cadeias produtivas e oportunidades de negócios na Amazônia. Belém: Convênio Unama-FCAP, 2002.

; SANTANA, R.L. Dinâmica e sustentabilidade do arranjo produtivo local da fruticultura na Amazônia In: FRUTAL AMAZÔNIA, 2008, Belém. Cidadania e desenvolvimento sustentável. Fortaleza: Frutal, 2008. v.3. p.1-14.

; CARVALHO, F.D. ; MENDES. T.A.F. Análise sistêmica da fruticultura paraense: organização, mercado e competitividade empresarial. Belém: Banco da Amazônia, 2008.

TOLEDO, G.L.; OVALLE, I.I. Estatística básica. São Paulo: Atlas, 1995. 